\title{
POTENCIAL CLIMÁTICO PARA A PRODUÇÃO DE UVAS EM CAMPOS DOS GOYTACAZES, REGIÃO NORTE FLUMINENSE ${ }^{1}$
}

\author{
CELSO VALDEVINO POMMER ${ }^{2}$, LUCIANE SIQUEIRA MENDES ${ }^{3}$, \\ LEANDRO HESPANHOL-VIANA ${ }^{4}$, RICARDO BRESSAN-SMITH ${ }^{5}$
}

RESUMO-O Sistema de Classificação Climática Multicritérios (Sistema Geovitícola CCM) baseado em três índices climáticos:o Índice de Seca (IS), que corresponde a um indicador do nível de seca; o Índice Heliotérmico (HI), que corresponde ao índice heliotérmico de Huglin, e o Índice de Frio Noturno (IF), que atua como um indicador das condições de temperatura noturna durante a maturação das bagas, possibilitaram a descrição do potencial climático de vinhedos no mundo todo. Neste trabalho, foi caracterizado o clima vitícola em períodos de crescimento e produção durante o ano com duração de quatro meses cada, na região norte fluminense, representada pelo município de Campos dos Goytacazes $\left(21^{\circ} 45^{\prime} \mathrm{S}, 41^{\circ} 19^{\prime} \mathrm{W}, 13\right.$ $\mathrm{m})$. O sistema indicou potencial para o cultivo da videira na região durante o ano, por meio de diferenças encontradas nos índices IS, IH e IF. Os períodos quadrimestrais de janeiro/abril, fevereiro/maio, março/ junho, abril/julho, maio/agosto, junho/setembro, julho/outubro e agosto/novembro foram considerados os mais adequados para o cultivo da videira, mostrado pelos índices: IS +1 indicando classe de Seca Moderada, IH-2 a IH-1, para classes Frias a Temperadas, exceto para janeiro/abril, com IH+1, para classe Temperada Quente, e IF-2 a IF-1 para classes de Noites Quentes a Temperadas. Em adição ao potencial climático mostrado, que permite adequado crescimento das plantas, as condições desses períodos também são satisfatórias pela diminuição da necessidade de pulverizações de defensivos e coincidindo com baixa oferta de uvas no mercado e preços mais elevados, o que torna a região apropriada para mais de um ciclo por ano. Neste trabalho, o sistema permitiu a distinção de períodos de cultivo da uva ao longo do ano, funcionando como uma ferramenta apropriada para o zoneamento vitícola.

Termos para indexação: videira, Vitis, clima, sistema CCM, índices climáticos.

\section{CLIMATIC POTENTIAL FOR GRAPE PRODUCTION IN THE NORTH REGION OF THE STATE OF RIO DE JANEIRO, BRAZIL}

\begin{abstract}
Multicriteria Climatic Classification System (Geoviticulture MCC System) based on three climate indexes, the dryness index (DI), which corresponds to an indicator of the dryness level, the heliothermal index (HI), which corresponds to Huglin's heliothermal index, and the cool night index (CI), that acts as an indicator of night temperature conditions during berry maturation, was able to describe the climatic potential for vineyards around the world. In this study we characterized the viticulture climate on twelve growth-production periods during a year with four months duration each, in the North region of the state of Rio de Janeiro, represented by Campos dos Goytacazes municipality (21 $\left.45^{\prime} \mathrm{S}, 41^{\circ} 19^{\prime} \mathrm{W}, 13 \mathrm{~m}\right)$. The system indicated that the region has potential for grape production during the year through markedly differences in DI, HI and CI indexes. The 4-months periods of January/April, February/May, March/June, April/July, May/August, June/September, July/October and August/November were considered the most suitable for grape production, as the indexes show: IS +1 indicating moderate drought class, IH- 2 to IH-1, for cold to temperate classes, except for January/April, with IH+1, for temperate warm class, and IF-2 to IF-1 from warm to temperate nights classes. It can be seen that these periods shows climatic potential, and as allowing adequate plant growth, are satisfactory also for diminishing needs of sprayings and coinciding with low product offer and higher prices, what turns the region with suitability for more than one cycle per year. In this study, the system allowed the distinction of periods of grape-growing throughout a year, acting as appropriate tool for viticulture zoning.
\end{abstract}

Index terms: grapevine, Vitis, climate, MCC system, indexes.

${ }^{1}$ (Trabalho 271-08). Recebido em: 31-10-2008. Aceito para publicação em: 21-07-2009.

${ }^{2}$ Professor Visitante, Universidade Estadual do Norte Fluminense - UENF, Campos-RJ. celso@uenf.br

${ }^{3}$ Estagiária do Setor de Fisiologia Vegetal - UENF. lucianerural@yahoo.com.br

${ }^{4}$ Doutorando, Universidade Estadual do Norte Fluminense - UENF. hespanhol@yahoo.com.br

${ }^{5}$ Professor Associado, UENF. Com bolsa de produtividade do CNPq. bressan@uenf.br

Rev. Bras. Frutic., Jaboticabal - SP, v. 31, n. 4, p. 1076-1083, Dezembro 2009 


\section{INTRODUÇÃO}

No agronegócio da uva e do vinho, é reverenciado o termo "terroir", que fornece um balizamento de critérios associados à qualidade de um vinho, em função do clima, do solo e da variedade da uva, entre outros (Tonietto, 2007). O termo traduz fundamentalmente a interação entre o meio natural, como o clima, o solo e o relevo, e os fatores dependentes da opção humana, como escolha das variedades, aspectos agronômicos na produção das uvas e aqueles usados na elaboração do vinho. Em última instância, ele está na base do conceito das denominações de origem, algo bastante conhecido e utilizado criteriosamente na Europa, cujos países detêm, por exemplo, um semnúmero de cepas autóctones, microclimas, solos e tradições. Distante de quase tudo isso, o Brasil tem sua produção de uvas, para mesa ou vinho, concentrada em algumas regiões como Rio Grande do Sul e São Paulo, e no Vale do Rio São Francisco, no polo vitícola Petrolina/Juazeiro, nos Estados de Pernambuco e Bahia.

Tonietto e Carbonneau (1999), a respeito de clima para a viticultura, comentam que o limite geográfico vitícola do globo, em superfície cultivada, é determinado pela restrição térmica. Por exemplo, no Hemisfério Norte, os vinhedos comerciais mais setentrionais encontram-se na Inglaterra, em torno do paralelo $52^{\circ}$, e no Hemisfério Sul, a viticultura está presente até $45^{\circ}$ de latitude, na Nova Zelândia. Tais limitações podem ser explicadas pelo emprego de índices climáticos, discutidos por Tonietto e Carbonneau (2004). Sobre o Índice Térmico de Winkler, que tornou possível a classificação da viticultura da Califórnia em cinco grandes regiões, de acordo com categorias de graus-dias, Tonietto e Carbonneau (1999) reportam que ele representa bem a qualidade da uva e algumas características dos vinhos ali produzidos como resultado da influência climática (Winkler, 1962). Quanto ao Índice Heliotérmico de Huglin - IH (Huglin, 1978), Tonietto e Carbonneau (1999) comentam que é aplicável a amplas regiões no mundo, pois é estabelecido para um período próximo ao ciclo médio de desenvolvimento da videira, levando em conta o comprimento do dia para altitudes elevadas e mostrando boa relação com o potencial teor de açúcar da uva. Tonietto e Carbonneau (1999) finalizam sua visão sobre esses dois índices, afirmando que eles são essencialmente térmicos ao longo do ciclo e não possibilitam distinção de climas em escala mundial, porque outros fatores climáticos devem ser levados em consideração.
Não por outras razões, Tonietto e Carbonneau (2004) enfatizam a necessidade e a adequação do uso de uma classificação climática multicritérios para regiões vitícolas que utilizem índices sintéticos relacionados com as necessidades das variedades, qualidade vinícola (açúcares, cor, aroma) e tipologia de vinhos. Por exemplo, o Índice de Frio Noturno IF, leva em conta as temperaturas mínimas noturnas durante o período de amadurecimento, e tem relação com o desenvolvimento das propriedades qualitativas das uvas, especialmente de polifenóis e de aromas (Kliewer e Torres, 1972). Outro índice a ser utilizado, o Índice de Seca - IS, avalia a disponibilidade hídrica do solo de um vinhedo de acordo com os níveis de seca que ocorrem em uma dada região. Esse índice tem relação com o amadurecimento das uvas e com a qualidade do vinho (Jackson e Cherry, 1988). Em resumo, o sistema de classificação climático multicritério, denominado por Tonietto e Carbonneau (2004) como Sistema CCM Geovitícola, tem como base: (1) o clima vitícola; (2) o grupo climático, e (3) o clima vitícola com variação intra-anual, para regiões com mais de uma colheita ao ano sob condições naturais. Usando tais conceitos, é possível aplicar o CCM Geovitícola em grande ou pequena escala, para grandes ou pequenas regiões produtoras. Tomando esses índices como bons indicadores, é possível classificar, portanto, regiões de grande potencial para a atividade vitícola.

No Brasil, pela maior expressão da vitivinicultura, calcada na produção de vinhos, os primeiros trabalhos visando a tipificar zonas vitícolas usando índices climáticos, iniciaram-se no Rio Grande do Sul, criando as chamadas Indicações Geográficas. Posteriormente, Tonietto e Carbonneau (2004) realizaram importante estudo, aplicando o Sistema CCM Geovitícola a 97 regiões produtoras de 29 países. Os autores concluíram que a enorme diversidade climática encontrada nas regiões avaliadas mostrou que o sistema utilizado tem grande precisão na classificação de climas vitícolas. Ainda utilizando o mesmo sistema, Tonietto et al. (2006) compararam diversas regiões potenciais para a viticultura em Minas Gerais e, após análises de componentes principais, definiram quatro agrupamentos que diferiram em sua potencialidade para o cultivo da uva para vinho naquele Estado.

Estudos têm mostrado que a região norte fluminense tem plenas condições de se estabelecer como polo produtor de uvas de mesa no Estado do Rio de Janeiro (Murakami et al., 2002). Mesmo que existam algumas descrições climáticas desta região para delinear a sua potencialidade para a viticultura 
(Murakami et al., 2002; Hespanhol-Viana et al., 2008), pode ser dito que as informações climáticas existentes ainda são insuficientes para fornecer descrição mais detalhada do seu potencial vitícola. Falta, portanto, uma avaliação criteriosa do potencial climático dessa região, utilizando índices climáticos apropriados, como o Sistema CCM Geovitícola. Contando que tal sistema admite avaliações intraanuais, sua aplicabilidade em regiões de clima tropical com mais de uma colheita anual, como é o caso do norte fluminense, tornará possível uma caracterização completa.

Com base nessas informações, o objetivo deste trabalho foi o de caracterizar o município de Campos dos Goytacazes, o maior da região norte fluminense, em relação ao ajuste de suas condições climáticas dentro do Sistema CCM Geovitícola. Tal avaliação é um passo fundamental no esforço de introduzir a viticultura na região supracitada para a produção de uvas em larga escala, destinadas ao consumo in natura e processadas.

\section{MATERIAL E MÉTODOS}

Foram utilizados dados meteorológicos do município de Campos dos Goytacazes-RJ $\left(21^{\circ} 45^{\prime} \mathrm{S}\right.$, $41^{\circ} 19^{\prime} \mathrm{W}, 13 \mathrm{~m}$ ). Os dados foram disponibilizados pelo Laboratório de Engenharia Agrícola (LEAG) da Universidade Estadual do Norte Fluminense Darcy Ribeiro (UENF) e tiveram por base a série histórica de 1997 a 2006. As análises foram realizadas empregando-se o Sistema CCM Geovitícola (Tonietto, 2008), que se baseia em três índices climáticos viticulturais sintéticos e complementares; o balanço hídrico potencial do solo e as condições heliotérmicas, ambos durante o ciclo de crescimento, e a temperatura noturna durante a maturação: (1) Índice Heliotérmico (IH), que corresponde ao índice heliotérmico de Huglin (1978) representando a soma térmica diurna (Tabela 1); (2) Índice de Frio Noturno (IF), desenvolvido como indicador das condições de temperatura noturna durante a maturação (valor médio da temperatura mínima do ar do último mês do período de maturação das uvas) (Tabela 2) (Tonietto e Carbonneau, 2004; Conceição e Tonietto, 2005); (3) Índice de Seca (IS), que corresponde ao balanço hídrico potencial do solo, da forma usada no índice de Riou, mas aqui adaptado usando condições precisas no seu cálculo, como um indicador do nível da presença ou ausência de seca (Tabela 3).

O período do ano para cálculo dos índices foi preconizado por Tonietto e Carbonneau (2004) como de $1 .^{\circ}$ de abril a 30 de setembro no Hemisfério Norte, e de $1 .^{\circ}$ de outubro a 31 de março, no Hemisfério
Sul, considerando o período de seis meses para o desenvolvimento da videira, da poda à colheita em regiões tradicionais. Esses períodos compreendem, em cada hemisfério, o período de primavera-verão, englobando as fases de desenvolvimento vegetativo e de produção e maturação das uvas, tornando possível a comparação entre diferentes regiões do globo.

O clima vitícola pode apresentar variabilidade intra-anual, frequente em regiões tropicais e subtropicais, mudando de classe de acordo com o período do ano em que a uva é produzida. No presente trabalho, a caracterização CCM Geovitícola para o município do norte fluminense levou em consideração avaliações em cada mês do ano, considerando sempre a duração de um ciclo vegetativo-produtivo de quatro meses. As variações térmicas e hídricas que ocorrem nessa região durante o ano são significativas.

\section{RESULTADOS E DISCUSSÃO}

Em termos de clima, a distribuição das chuvas, no período de 1997 a 2006, e os valores médios mensais das temperaturas máximas e mínimas são apresentados nas Figuras 1 e 2. As precipitações pluviométricas mensais são maiores nos meses considerados quentes e úmidos, que vão de setembro a maio, e menores nos meses considerados frios e secos, entre junho e agosto. As temperaturas máximas e mínimas seguem padrão relativamente semelhante, com leve redução entre os meses de junho e agosto em relação aos demais meses do ano.

O Índice de Seca - IS, calculado teve variação entre $-35,4$ e 188,4 . Pela Tabela 1, conclui-se que os períodos de quatro meses, correspondentes ao ciclo vegetativo-produtivo para a região, que se iniciaram entre os meses de janeiro e agosto, são representativos da classe IS $_{+1}$, ou de Seca Moderada. Os períodos que se iniciaram nos meses de setembro, outubro e novembro, foram representativos da classe $\mathrm{IS}_{-2}$, ou Úmida. Um único período, que se iniciou em dezembro, foi representativo da classe $\mathrm{IS}_{-1}$, ou Subúmido (Tabela 4).

Maior variação foi observada no Índice Heliotérmico - IH, sendo considerados como Temperado os períodos de ciclo vegetativoreprodutivo que se iniciaram em fevereiro e março, e depois em setembro e outubro. A classe considerada como Frio pelo IH, foi representada pelos períodos que se iniciaram entre abril e agosto. Uma terceira classe, a Temperado Quente, foi representada 
pelos períodos iniciados nos meses de novembro, dezembro e janeiro (Tabela 4).

Para o Índice de Frio Noturno - IF, os períodos de ciclo vegetativo-produtivo, que se iniciaram nos meses de fevereiro a junho, foram representativos da classe Noites Temperadas. Para os períodos que se iniciaram nos meses de julho a janeiro, a classe representativa foi a de Noites Quentes (Tabela 4).

Esses valores de IH, IF e IS dão uma primeira indicação da existência de períodos diferenciados ao longo do ano. Considerando que as temperaturas da região são elevadas (Fig. 2), vislumbra-se a possibilidade de produção de uvas com colheita em mais de uma ocasião por ano e em épocas diferentes, como descrito por Murakami et al. (2002) e Hespanhol-Viana et al. (2008). Na Tabela 4, estão dispostos os resultados obtidos com os índices preconizados por Tonietto e Carbonneau (2004) para Campos dos Goytacazes. Existe variação intra-anual, mostrando poucas classes de clima vitícola. Os períodos de setembro/ dezembro, outubro/janeiro, novembro/fevereiro e dezembro/março, porém, apresentam condições claramente tropicais, com os índices pouco variando: $\mathrm{IS}_{-2}$ a IS $\mathrm{IS}_{-1}$, denotando Classe Úmida e Subúmida; $\mathrm{IH}_{+1}$ a $\mathrm{IH}_{-1}$, para classe Temperado e Temperado Quente; e IF ${ }_{-2}$. para classe Noites Quentes. Tais condições são propícias para a produção de uvas de mesa muito embora o estabelecimento do ciclo vegetativo-produtivo seja variável com diferentes cultivares. Para se ter uma ideia, Hespanhol-Viana et al. (2008) mostraram que o ciclo de produção da Niagara Rosada em São Fidélis-RJ, município localizado no norte fluminense, podada em janeiro, durou 103 dias. Tal ciclo, apesar de estar um mês além dos períodos supracitados, mostra que, além do período ser considerado de Noite Quente e Temperado Quente, destaca-se por ser de Seca Moderada. Por isso, considera-se que outros períodos também poderão ter condições para a produção de uvas de mesa, e até mesmo de uvas para vinho.

Outro trabalho que corrobora esta afirmativa foi realizado por Murakami et al. (2002), em experimento com a cv. Itália no município de Cardoso Moreira, na região norte fluminense. Durante o ano de 2001, os autores estimaram a necessidade térmica em graus-dia (GD), sob diferentes épocas de poda (abril, maio, junho e julho) e avaliaram os períodos de poda à gema algodão, gema algodão à brotação, brotação ao aparecimento da inflorescência, aparecimento da inflorescência ao florescimento, florescimento ao início da maturação e início da maturação à colheita. Verificaram que a duração do ciclo foi de 138; 151; 150 e 157 dias para podas realizadas nos meses de abril, maio, junho e julho, respectivamente. A soma térmica necessária foi de 1.727GD para poda realizada em abril, 1.564GD para poda realizada em maio, 1.702GD para poda realizada em junho e 1.840GD para poda realizada em julho, utilizandose de temperatura-base de $12^{\circ} \mathrm{C}$.

Conforme observado por Conceição e Tonietto (2005), para a região norte de Minas Gerais, parece haver também certa semelhança entre o norte fluminense e a região do Submédio São Francisco, visto que a produção de uvas pode ser realizada durante o ano inteiro. Em comparação com o encontrado por Conceição e Tonietto (2005) para o norte de Minas Gerais, o período de produção (primavera-verão, $\mathrm{PV}$ ) foi classificado como $\mathrm{IH}+3$ (muito quente) em Pirapora e Montes Claros. Da mesma forma, o Índice de Frio Noturno (IF), durante o mesmo período, foi classificado como IF-2 (de noites quentes) em Pirapora e Montes Claros. Os autores sugerem que, devido aos altos valores da precipitação pluvial e das temperaturas, o período PV pode ser usado para a formação dos ramos, preparando as plantas para um novo ciclo. Pela experiência prévia (Hespanhol-Viana et al., 2008; Murakami et al., 2002), e diante dos valores encontrados para Campos dos Goytacazes, no norte fluminense, parece razoável que se interprete como real potencial climático para a produção de uvas em diferentes épocas do ano. O produtor poderá valer-se disso para gerenciar suas operações de poda, visando a obter suas colheitas em épocas mais favoráveis. Conforme estabeleceram Conceição e Tonietto (2005), a comparação com outras regiões indica o potencial climático da região estudada, muito embora o desenvolvimento da cultura em condições tropicais, sobretudo se considerado o período de início de OI, apresente uma dinâmica diferenciada em relação às regiões de clima temperado (Pommer, 2006).

Tonietto e Teixeira (2004), analisando o desenvolvimento da cv. Syrah na região semiárida do vale do São Francisco, empregaram as funções de modulação dos índices de Tonietto e Carbonneau (2004). Naquelas condições, a cv. Syrah tem ciclo médio de 4 meses, da brotação à colheita, semelhante, portanto, ao obtido por Hespanhol-Viana et al. (2008) para Niágara Rosada no norte fluminense. Tonietto e Teixeira (2006) simularam 36 colheitas teóricas por ano, calculando o Índice Heliotérmico $\left(\mathrm{IH}_{12 \mathrm{~d}}\right)$ a cada 4 meses ao longo do ano; o Índice de Frio Noturno $\left(\mathrm{IF}_{3 \mathrm{~d}}\right)$ foi calculado para os 30 
dias que precederam a colheita teórica (período de maturação) e a quantidade de chuva no período de maturação $\left(\mathrm{P}_{3 \mathrm{~d}}\right)$ levou igualmente em conta o efeito potencial de incidência de podridão dos cachos, mas esses autores não utilizaram, nesse estudo, o Índice de Seca (IS). Os resultados possibilitaram distinguir três períodos viticulturais climáticos durante o ano: período "a" menos quente durante o ciclo brotaçãocolheita (b-c) $\left(\mathrm{IH}_{12 \mathrm{~d}}\right)$, temperaturas noturnas $\left(\mathrm{IF}_{3 \mathrm{~d}}\right)$ mais frescas e muito seco $\left(\mathrm{P}_{3 \mathrm{~d}}\right)$; período " $\mathrm{b}$ " intermediário entre os períodos "a" e "c" para IF e IH e seco a muito seco; período "c" o mais quente para IH e IF e subúmido. Os autores concluíram que os períodos "a" e "b" , mesmo com diferentes potenciais climáticos para a viticultura, são os mais favoráveis para a produção daquela uva.

Neste estudo, embora com valores elevados, o IH apresentou grande variabilidade ao longo do ano, de 1.649 a 2.208, mais ampla do que a observada por Tonietto e Teixeira (2004) para o vale do São Francisco. O IF variou de 15,6 a $21,7^{\circ} \mathrm{C}$, também mais amplo; IS, de -35,4 a 188,4, bastante amplo.

Aplicando-se os índices aos períodos, verifica-se grande semelhança entre março/junho, abril/julho, maio/agosto e junho/setembro, com IS+1, IF-1 e IH+2. A literatura (Conceição e Tonietto, 2005; Tonietto e Carbonneau, 2004) indica que essa classificação climática é a mesma encontrada em Pirapora e Montes Claros, região produtora de uvas de mesa em Minas Gerais, no período OI (IS+1 IH+2 IF-1), assemelhando-se à da região vitícola de Múrcia (Espanha).

Entretanto, ainda se assemelham os períodos janeiro/abril, com IS+1, IF-2 e IH+3, fevereiro/ maio com IS+1, IF-1 e IH+3 e julho/outubro e agosto/novembro com IS+1, IF-2 e IH+2.

$\mathrm{Na}$ Figura 3, fica nítida a distinção entre os períodos, delineada pela linha vertical. Os períodos quadrimestrais indicados pela letra "a" podem ser considerados os mais apropriados para a produção de uvas em Campos dos Goytacazes e, por extensão, no norrte fluminense. É importante destacar que as épocas de colheita nesses quadrimestres coincidem com a menor oferta de uvas no mercado e, consequentemente, os melhores preços. Aliese, ainda, à menor quantidade de chuvas nesses períodos, à menor incidência de doenças, facilitando seu controle.

Embora se tenham feito essas afirmações levando em conta o ciclo de menos de quatro meses para a cultivar Niágara Rosada (Hespanhol-Viana et al., 2008), é perfeitamente admissível extrapolar os resultados para a cultivar Itália, com ciclo de pouco mais de cinco meses (Murakami et al., 2002), bastando uma pequena adequação para os períodos, passando-os para janeiro/maio, fevereiro/ junho, março/julho, abril/agosto, maio/setembro e junho/outubro.

TABELA 1 - Classe, sigla e intervalo de classe para o Índice Heliotérmico (Conceição e Tonietto, 2005).

\begin{tabular}{lcc}
\hline Classe & Sigla & Intervalo $\left({ }^{\circ} \mathbf{C}\right)$ \\
\hline Muito frio & $\mathrm{IH}_{-3}$ & $\leq 1500$ \\
Frio & $\mathrm{IH}_{-2}$ & $>1500 \leq 1800$ \\
Temperado & $\mathrm{IH}_{-1}>1800 \leq 2100$ \\
Temperado Quente & $\mathrm{IH}_{+1}>2100 \leq 2400$ \\
Quente & $\mathrm{IH}_{+2}>2400 \leq 3000$ \\
Muito Quente & $\mathrm{IH}_{+3}$ & $>3000$ \\
\hline
\end{tabular}

Cálculo do Índice Heliotérmico (Tonietto e Carbonneau, 2004):

$I H=\sum_{01.04}^{30.09} \frac{\left[(T-10)+\left(T_{x}-10\right)\right]}{2} \times k \quad$, no qual: $\mathrm{T}=$ temperatura média do ar $\left({ }^{\circ} \mathrm{C}\right), \mathrm{Tx}=$ temperatura máximado $\operatorname{ar}\left({ }^{\circ} \mathrm{C}\right), \mathrm{k}=$ coeficiente comprimento do dia, considerado 1,0 para latitudes abaixo de $40^{\circ}$.

TABELA 2- Classe, sigla e intervalo de classe para o Índice de Frio Noturno (Conceição e Tonietto, 2005).

\begin{tabular}{lcc}
\hline Classe & Sigla & Intervalo $\left({ }^{\circ} \mathbf{C}\right)$ \\
\hline De noites quentes & $\mathrm{IF}_{-2}$ & $>18$ \\
De noites temperadas & $\mathrm{IF}_{-1}$ & $>14 \leq 18$ \\
De noites frias & $\mathrm{IF}_{+1}$ & $>12 \leq 14$ \\
De noites muito frias & $\mathrm{IF}_{+2}$ & $\leq 12$ \\
\hline
\end{tabular}

Cálculo do Índice de Frio Noturno (Tonietto e Carbonneau, 2004): IF = Tn 09, no qual:

Tn 09 (no Hemisfério Norte - média das mínimas em ${ }^{\circ} \mathrm{C}$ ) = temperatura mínima do ar do mês de setembro; Tn 03 (no Hemisfério Sul - média das mínimas em ${ }^{\circ} \mathrm{C}$ ) = temperatura mínima do ar do mês de março. 
TABELA 3 - Classe, sigla e intervalo de classe para o Índice de Seca (Conceição e Tonietto, 2005).

\begin{tabular}{lcc}
\hline Classe & Sigla & Intervalo (mm) \\
Úmido & IS $_{-2}$ & $>150$ \\
Subúmido & IS $_{-1}$ & $<150>50$ \\
De seca moderada & IS $_{+1}$ & $<50>-100$ \\
De seca forte & IS $_{+2}$ & $<-100$ \\
\hline
\end{tabular}

Cálculo (Tonietto e Carbonneau, 2004): IS = Wo + P - TV - ES no qual: IS = reserva hídrica do solo potencial; Wo = reserva hídrica inicial útil do solo; $\mathrm{P}=$ precipitação pluviométrica; $\mathrm{TV}=$ transpiração potencial do vinhedo; ES = evaporação direta a partir do solo.

TABELA 4 - Resumo dos resultados obtidos com os índices climáticos em diferentes períodos do ano, em Campos dos Goytacazes-RJ.

\begin{tabular}{lccccccc}
\hline Período & IS & Sigla & IF & Sigla & IH & Sigla & Sigla* \\
\hline Jan/abr. & 47,7 & $\mathrm{IS}_{+1}$ & 20,3 & $\mathrm{IF}_{-2}$ & 2193,7 & $\mathrm{IH}_{+1}$ & $\mathrm{IH}_{+3}$ \\
Fev/maio & 21,8 & $\mathrm{IS}_{+1}$ & 17,3 & $\mathrm{IF}_{-1}$ & 2071,3 & $\mathrm{IH}_{-1}$ & $\mathrm{IH}_{+3}$ \\
Mar/jun. & 19,6 & $\mathrm{IS}_{+1}$ & 16,2 & $\mathrm{IF}_{-1}$ & 1920,7 & $\mathrm{IH}_{-1}$ & $\mathrm{IH}_{+2}$ \\
Abr/jul. & 5,6 & $\mathrm{IS}_{+1}$ & 15,6 & $\mathrm{IF}_{-1}$ & 1778,6 & $\mathrm{IH}_{-2}$ & $\mathrm{IH}_{+2}$ \\
Mai/ago. & $-22,4$ & $\mathrm{IS}_{+1}$ & 16,4 & $\mathrm{IF}_{-1}$ & 1692,8 & $\mathrm{IH}_{-2}$ & $\mathrm{IH}_{+2}$ \\
Jun/set. & $-34,5$ & $\mathrm{IS}_{+1}$ & 17,6 & $\mathrm{IF}_{-1}$ & 1649,7 & $\mathrm{IH}_{-2}$ & $\mathrm{IH}_{+2}$ \\
Jul/out. & $-35,4$ & $\mathrm{IS}_{+1}$ & 18,7 & $\mathrm{IF}_{-2}$ & 1709,7 & $\mathrm{IH}_{-2}$ & $\mathrm{IH}_{+2}$ \\
Ago/nov. & 40,9 & $\mathrm{IS}_{+1}$ & 20,0 & $\mathrm{IF}_{-2}$ & 1776,8 & $\mathrm{IH}_{-2}$ & $\mathrm{IH}_{+2}$ \\
Set/dez. & 162,4 & $\mathrm{IS}_{-2}$ & 21,3 & $\mathrm{IF}_{-2}$ & 1877,0 & $\mathrm{IH}_{-1}$ & $\mathrm{IH}_{+2}$ \\
Out/jan. & 188,4 & $\mathrm{IS}_{-2}$ & 21,6 & $\mathrm{IF}_{-2}$ & 2042,5 & $\mathrm{IH}_{-1}$ & $\mathrm{IH}_{+3}$ \\
Nov/fev. & 168,9 & $\mathrm{IS}_{-2}$ & 21,7 & $\mathrm{IF}_{-2}$ & 2133,1 & $\mathrm{IH}_{+1}$ & $\mathrm{IH}_{+3}$ \\
Dez/mar. & 71,2 & $\mathrm{IS}_{-1}$ & 21,5 & $\mathrm{IF}_{-2}$ & 2208,1 & $\mathrm{IH}_{+1}$ & $\mathrm{IH}_{+3}$ \\
\hline indicede sec; & $\mathrm{IH}=$ índice heliotérmico; IF $=$ hindice de frio $^{-}$ & &
\end{tabular}

IS = índice de seca; $\mathrm{IH}=$ índice heliotérmico; $\mathrm{IF}=$ índice de frio noturno; *extrapolando o somatório para o período de seis meses

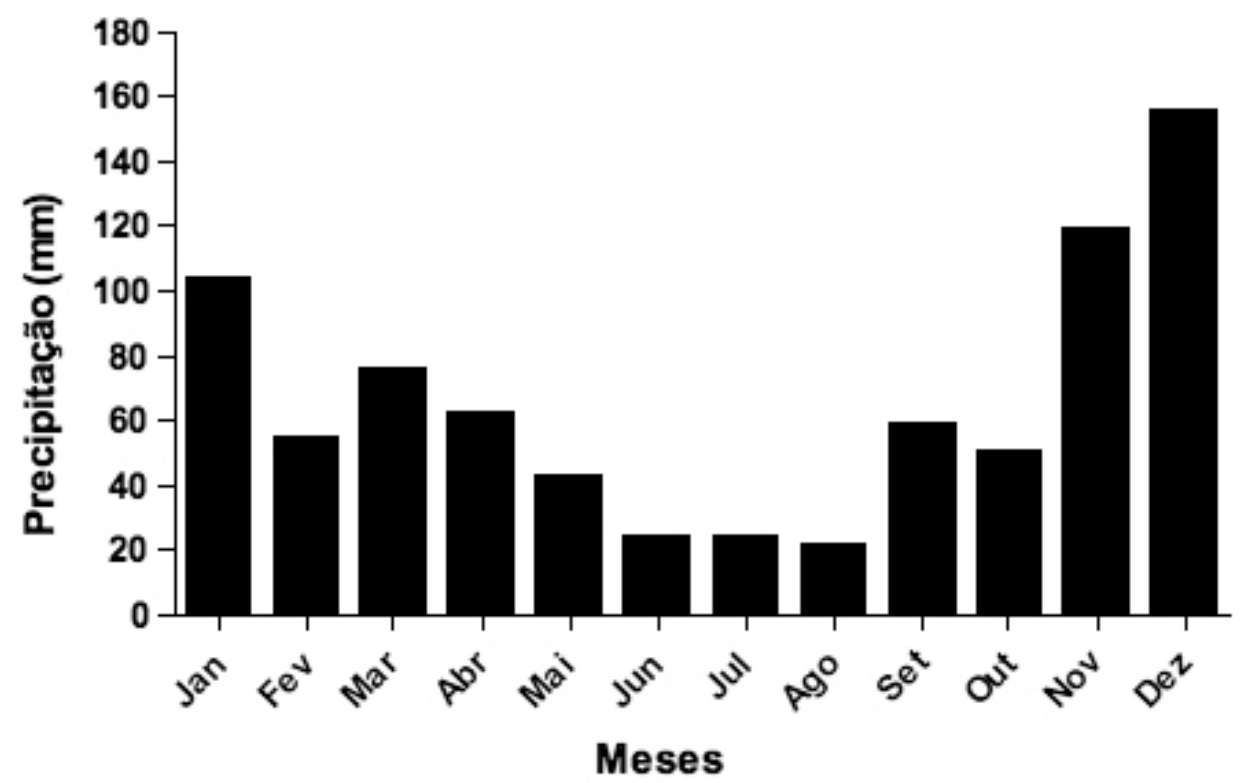

FIGURA 1-Precipitação pluviométrica média mensal em Campos dos Goytacazes-RJ, para o período de 1997 a 2006. Fonte: Universidade Estadual do Norte Fluminense. 


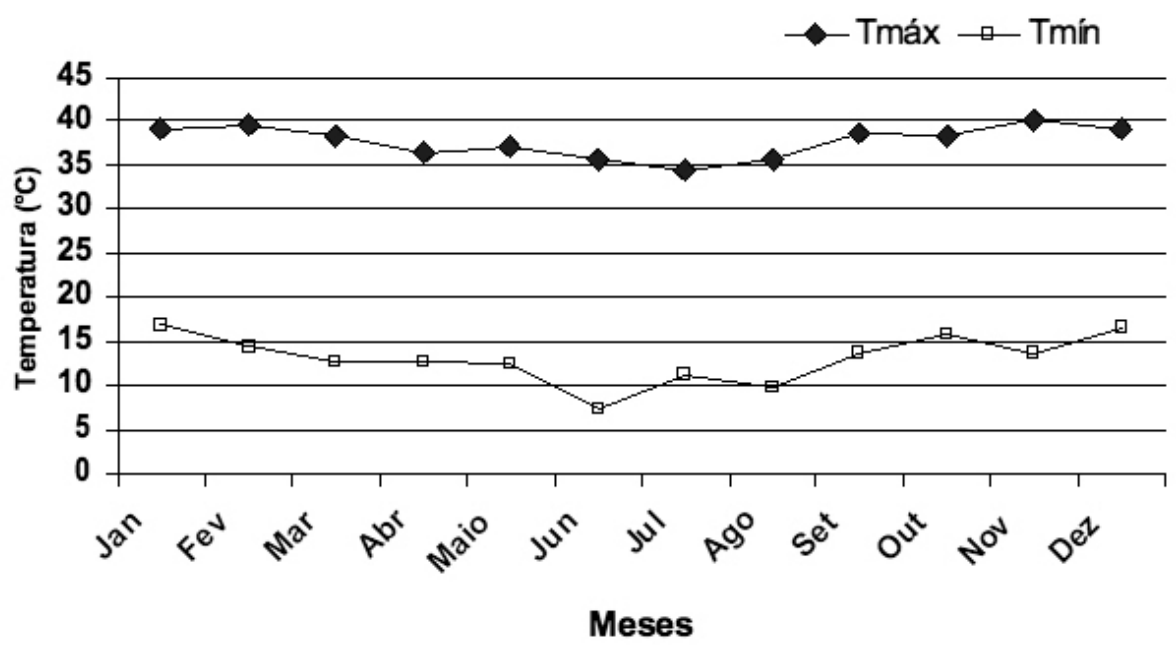

FIGURA 2-Médias mensais das temperaturas máxima e mínima em Campos dos Goytacazes-RJ, para o período de 1997 a 2006. Fonte: Universidade Estadual do Norte Fluminense

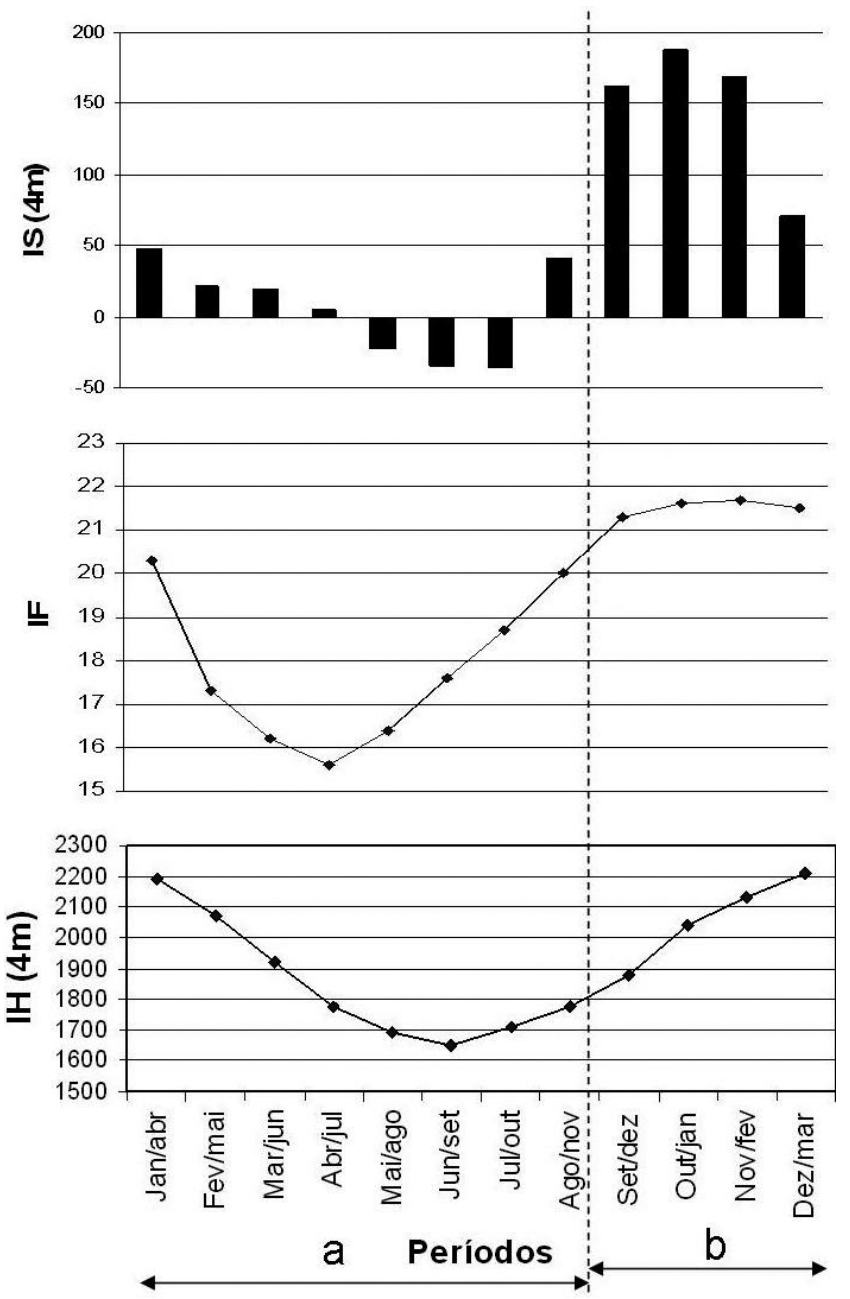

FIGURA 3-Variação dos índices de seca (IS), de frio noturno (IF) e heliotérmico (IH) ao longo do ano, em Campos dos Goytacazes, região norte fluminense. 


\section{CONCLUSÕES}

1-O município de Campos dos Goytacazes, no norte fluminense, apresenta aptidão climática para produção de uvas.

2-É possível obter colheita de uvas em mais de uma época durante o ano nessa região.

3-As melhores épocas para a exploração da videira nessa região, da poda à colheita, são as que coincidem com temperaturas menos elevadas $(\mathrm{IH}+2)$, com a presença de seca moderada (IS+1) e com noites temperadas (IF-1).

4-O Sistema CCM Geovitícola mostrouse uma ferramenta valiosa para o uso dos dados climáticos da região e sua interpretação na viticultura, permitindo a comparação com outras regiões.

\section{REFERÊNCIAS}

CONCEIÇÃO, M.A.F. ; TONIETTO, J. Potencial climático da região norte de Minas Gerais para a produção de uvas destinadas à elaboração de vinhos finos. Bento Gonçalves: Embrapa, 2005. 3p. (Comunicado Técnico, 56).

HESPANHOL-VIANA, L.; GUIMARÃES, J.C.; POMMER, C.V.; BRESSAN-SMITH, R. Fenologia da videira 'Niagara Rosada' (Vitis sp.) sob duas épocas de poda na região norte do Estado do Rio de Janeiro. In: CONGRESSO BRASILEIRO DE FRUTICULTURA, 20., 2008. Vitória. Anais...

HUGLIN, P. Nouveau mode d'évaluation des possibilites héliothermiques d'un milieu viticole. In: SYMPOSIUM INTERNATIONAL SUR L'ECOLOGIE DE LA VIGNE. MINISTERE DE L'AGRICULTURE ET DE L'INDUSTRIE ALIMENTAIRE, 1978, Constança. Proceedings... p.89-98.

MURAKAMI, K.R.N.; CARVALHO, A.J.C. de; CEREJA, B.S.; BARROS, J.C.S.M.; MARINHO, C.S. Caracterização Fenológica da Videira cv.Itália (Vitis vinifera L.) sob Diferentes Épocas de Poda na região Norte do Estado do Rio de Janeiro. Revista Brasileira de Fruticultura, Jaboticabal, v.24, p.615 - 617, 2002.
POMMER, C.V. Double Cropping of Table Grapes in Brazil. Chronica Horticulturae, Leuven, v.46, n.2, p.22-25. 2006.

TONIETTO, J. Metodologia do sistema CCM Geovitícola. Disponivel em: <http://www.cnpuv. embrapa.br/tecnologias $/ \mathrm{ccm} / \mathrm{met} . h \mathrm{tml}>$. Acesso em: maio 2008.

TONIETTO, J. Afinal, o que é Terroir? Bon Vivant, Flores da Cunha, v. 8, n. 98, p. 8, 2007.

TONIETTO, J.; CARBONNEAU, A. A multicriteria climatic classification system for grape-growing regions worlwide. Agricultural and Forest Meteorology, Amsterdan, v. 124, p. 81-97, 2004.

TONIETTO, J.; CARBONNEAU, A. Análise mundial do clima das regiões vitícolas e de sua influência sobre a tipicidade dos vinhos: a posição da viticultura brasileira comparada a 100 regiões em 30 países. In: CONGRESSO BRASILEIRO DE VITICULTURA E ENOLOGIA, 9., 1999, Bento Gonçalves. Anais... Bento Gonçalves: Embrapa Uva e Vinho, 1999 b. p.75-90.

TONIETTO, J.; TEIXEIRA, A.H. de C. Climatic zoning of viticultural production periods over the year in the tropical zone: application of the methodology of the Geoviticulture MCC System. In: JOINT INTERNATIONAL CONFERENCE ON VITICULTURAL ZONING, 2004, Cape Town. Proceedings... Cape Town: African Society for Enology and Viticulture, 2004. p.193-201. CD-ROM

TONIETTO, J.; VIANELLO, R.L.; REGINA, M.A. Caracterização macroclimática e potencial enológico de diferentes regiões com vocação vitícola em Minas Gerais. Informe Agropecuário, Belo Horizonte, v.27, n.234, p.32-55, 2006.

WINKLER, A.J. General viticulture. Berkeley, University of California, Berkeley, 1962. 633 p. 